\title{
Effect of Penetration Enhancers on Transdermal Delivery of Propofol
}

\author{
Keisuke Yamato, ${ }^{a}$ Yuri Takahashi, ${ }^{*}, b$ Hidero AkiYama, ${ }^{c}$ Kazuyuki Tsuji, ${ }^{c}$ Hiraku Onishi, ${ }^{a}$ and \\ Yoshiharu MACHIDA ${ }^{a}$ \\ ${ }^{a}$ Department of Drug Delivery Research, Hoshi University; 2-4-41 Ebara, Shinagawa-ku, Tokyo 142-8501, Japan: \\ ${ }^{b}$ Department of Physical Pharmacy, Nihon Pharmaceutical University; 10281 Komuro, Ina-cho, Kitaadachi-gun, Saitama \\ 362-0806, Japan: and ${ }^{c}$ Medical Information Services, Inc.; 3-6-18-403 Koyama, Shinagawa-ku, Tokyo 142-0062, Japan. \\ Received July 22, 2008; accepted December 26, 2008; published online January 15, 2009
}

To develop a transdermal dosage form of propofol (PF), in vitro skin permeability and in vivo absorbability of PF were investigated in rats, and the effectiveness of enhancers on the transdermal delivery of PF was estimated. Propylene glycol (PG), isopropyl myristate and macrogol were used as co-solvent type enhancers. $L(-)$ Menthol (MEN), D(+)-limonene, oleic acid, stearic acid, sucrose fatty acid esters and sodium dodecyl sulfate (SDS) were used as membrane-acting type enhancers. Among the co-solvent type enhancers, PG showed the highest enhancing effect in vitro. Furthermore, the synergistic effect of the combined use of PG and membraneacting type enhancers was confirmed. Higher values of permeation parameters were observed with the combined use of PG and MEN, sucrose fatty acid esters or SDS. For the in vivo experiment, the addition of a smaller amount of PG was preferable to the amount used in the in vitro experiment. The synergistic effect of enhancers was observed with the combined use of PG and MEN. Our findings suggest that the combination of PG and MEN was useful as enhancers for the transdermal absorption of PF. These results provide useful information to develop a transdermal dosage form of PF as a sedative or a hypnotic.

Key words transdermal drug delivery; skin permeability; propofol; enhancer; anesthetic

Transdermal therapeutic systems, intended to deliver a drug across skin for systemic activity, are receiving attention because these systems can (1) avoid hepatic first-pass metabolism, (2) maintain blood drug levels for an extended period of time by controlling the drug-release rate and (3) allow easy interruption of drug delivery. ${ }^{1,2)}$ However, the stratum corneum is known to be a major barrier to drug permeation through the keratinized epithelium. Due to the poor skin permeation of drugs, transdermal administration is often limited. ${ }^{3)}$ For enhancing drug delivery across the skin, the efficacy of penetration enhancers has been investigated. ${ }^{4}$ The penetration enhancers are generally classified as membraneacting types or co-solvent types. The membrane-acting types, such as fatty acid, ${ }^{5-7}$ terpene ${ }^{8-10}$ and surfactant, ${ }^{11-13)}$ achieve effects using small amounts by altering the condition of the lipid membrane constituting the stratum corneum. The co-solvent types, such as propylene glycol (PG), ${ }^{10,14)}$ polyethylene glycol $^{15}$ ) and ethanol, ${ }^{8)}$ achieve effects by improving the solubility of drugs or enhancing permeation of drugs through the skin.

Propofol (PF), a lipophilic anesthetic, is widely used clinically as it (1) has a rapid onset and cessation of effects upon intravenous infusion, (2) accumulates little and induces a brief but profound anesthesia, (3) maintains a level in circulation similar to the levels achieved by inhalation anesthetics. The characteristics of PF, lipophilicity and low molecular weight $(\mathrm{MW}=178)$, is suited to the transdermal delivery. $\left.{ }^{16}\right)$ Furthermore, as PF exists in the liquid state above $20^{\circ} \mathrm{C}$, a high-concentration PF solution can be prepared. In the previous study, we confirmed that PF was absorbed through rat skin and induced a sedative effect in rats. ${ }^{17)}$ By transdermal delivery of PF, the blood level of the drug can be maintained for an extended period of time. Hence, a possibility that PF can be developed as a transdermal dosage form of sedative or hypnotic is considered. In this study, the in vitro skin permeability and the in vivo absorbability of PF were investigated in rats using PF solutions containing various types of enhancers. Then, we estimated the effectiveness of enhancers on the transdermal delivery of PF.

\section{MATERIALS AND METHODS}

Materials PF was purchased from Clariant Corp. (Muttentz, Switzerland). Stearic acid (SA) was obtained from Kanto Chemical Co., Ltd. (Tokyo, Japan). Acetonitrile, ethanol, methanol, oleic acid (OA), sodium dodecyl sulfate (SDS), propylene glycol (PG), isopropyl myristate (IPM), L(-)-menthol (MEN), D(+)-limonene (LIM) and phosphoric acid were purchased from Wako Pure Chemical Industries, Ltd. (Osaka, Japan) as the purest grade available. Macrogol 400 (MG) was of Japanese Pharmacopoeia (JP) grade. Sucrose fatty acid esters were obtained from MitsubishiKagaku Foods Corporation (Tokyo, Japan). We used four kinds of sucrose fatty acid esters (L595, L1695, O1570 and S1570). L, O and S indicate lauric acid, oleic acid and stearic acid, respectively. The hydrophilic lipophilic balance (HLB) values of L595, L1695, O1570 and S1570 were 5, 16, 15 and 15 , respectively. All other chemicals were obtained commercially as the purest grade available.

Animals Male Sprague-Dawley rats weighing approximately 200-220 g were purchased from Tokyo Laboratory Animals Science Co., Ltd. (Tokyo, Japan). The experimental protocol was approved by the Ethics Review Committee for Animal Experimentation of Hoshi University. The guidelines for animal experimentation at Hoshi University conform to the basic guidelines published by the Ministry of Education, Culture, Sports, Science and Technology of Japan.

In Vitro Transdermal Permeation Experiments After sacrifice using ether, the abdominal hair was removed using an electric clipper, and the abdominal skin was excised and mounted on flow-through Franz diffusion cells. ${ }^{18)}$ The exposed skin area was $0.785 \mathrm{~cm}^{2}$ and test solutions $(0.5 \mathrm{ml})$ 
were applied onto the epidermal side of the skin as a donor solution. Since PF was insoluble in aqueous solution, phosphate buffer ( $\mathrm{pH} 7.4$ ) containing $10 \%(\mathrm{v} / \mathrm{v})$ methanol was used as a receiver solution. The solubility of PF to the receiver solution was measured. A sufficient amount of PF was added to the receiver solution, and stirred for $24 \mathrm{~h}$ at room temperature. The concentration of PF was measured by HPLC. The saturation solubility of PF to the receiver solution was $441 \mu \mathrm{g} / \mathrm{ml}$. It was considered that there was sufficient solubility of PF in the receiver solution. The receiver solution was magnetically stirred and maintained at $37^{\circ} \mathrm{C}$, and pumped through the diffusion cell by a Micro tube pump MP-3 (Tokyo Rikakikai, Tokyo) at a flow rate of approximately $45 \mathrm{ml} / \mathrm{h}$, and the spilled solution was collected in a glass flask. PF concentration in the spilled solution collected during a constant period was determined by HPLC after filtration using Acro LC13, $0.45 \mu \mathrm{m}$ (Nihon Pall Ltd., Tokyo, Japan). A $20-\mu 1$ aliquot of the filtrate was injected into the HPLC system. ${ }^{19)}$ HPLC was carried out using an LC-6AD pump and a C-R7A plus chromatopac (Shimadzu, Kyoto, Japan) equipped with a Neopack $C_{18}$ column $(4.6 \mathrm{~mm} \times$ $250 \mathrm{~mm}$, Nishio Industry Co., Ltd., Tokyo, Japan) and a model RF-10A XL fluorescence detector (Shimadzu) set at $276 \mathrm{~nm}$ of excitation and $310 \mathrm{~nm}$ of emission. The mobile phase was composed of acetonitrile-water-phosphoric acid (85\%): $60-40-0.2$ and the flow rate was set at $1.3 \mathrm{ml} / \mathrm{min}$. Chromatography was carried out at $30^{\circ} \mathrm{C}$.

Test Solutions for in Vitro Experiments Liquid state PF $(100 \%$ PF) and PF solutions containing $10-40 \%(\mathrm{w} / \mathrm{w})$ PG, 5-30\% (w/w) IPM and 5-30\% (w/w) MG were prepared as donor solutions to investigate the enhancing effects of co-solvent type enhancers. PF solutions containing 2.5$7.5 \%(\mathrm{w} / \mathrm{w}) \mathrm{MEN}, 5-20 \%(\mathrm{w} / \mathrm{w})$ LIM, 2.5-7.5\% (w/w) OA, $2.5-5 \%(\mathrm{w} / \mathrm{w}) \mathrm{SA}$ and $1 \%(\mathrm{w} / \mathrm{w})$ sucrose fatty acid esters (L595, L1695, O1570 and S1570) were also prepared to investigate the enhancing effects of membrane-acting type enhancers. Furthermore, the combined effects of these enhancers were investigated. PF solutions containing PG with MG or IPM were prepared as donor solutions. Combined effect of PG and membrane-acting type enhancers was also investigated. PF solutions containing PG with MEN, LIM, OA, SA, sucrose fatty acid esters or SDS were prepared as donor solutions. All test solutions were mixed enough before use until becoming visually clear liquid.

Data Analysis Flux ( $\left.J_{S s}\right)$ was calculated from the slope of the linear portion of cumulative amount permeated-time plots for a zero-order model and expressed as the mass of PF passing across $1 \mathrm{~cm}^{2}$ of skin over time. Permeation coefficient $(k p)$ was calculated using the following equation:

$$
k p=J_{s s} / \mathrm{Cs}
$$

where Cs represents PF concentrations $(\mathrm{g} / \mathrm{g})$ in donor solutions. Then, $k p$ was compared to estimate the enhancing effects of enhancers on transdermal permeation of PF.

In Vivo Transdermal Absorption Experiments Rats were intraperitoneally anesthetized with pentobarbital sodium $(6.25 \mathrm{mg} / \mathrm{kg})$ and fixed on their backs. The hair of the abdominal skin was removed carefully with electric clippers. A glass cell (application area: $6.15 \mathrm{~cm}^{2}$, height: $3.0 \mathrm{~cm}$ ) was placed on the clipped region using surgical adhesive. After the adhesive had hardened completely, the test solutions
$(1.3 \mathrm{ml})$ were put into the glass cell. As test solutions, $100 \%$ PF and PF solutions containing $1-30 \%$ PG were used. Furthermore, PF solutions containing $\mathrm{PG}$ and MEN, SDS or sucrose fatty acid esters were also studied. To prevent volatilization of the test solution, the glass cell was covered with aluminum foil. Blood samples $(300 \mu \mathrm{l})$ were periodically collected from the jugular vein after application of the test solutions. After centrifugation, the plasma was separated and stored at $-70{ }^{\circ} \mathrm{C}$ until analysis. The abdominal skin under the test solutions was investigated visually when the experiment ended.

The plasma concentration of PF was measured by HPLC. Ethanol $(200 \mu \mathrm{l})$ was added to the plasma $(100 \mu \mathrm{l})$ and the mixture was centrifuged at $4800 \boldsymbol{g}$ for $5 \mathrm{~min}$ after adequate agitation followed by standing for $10 \mathrm{~min}$. Twenty microliters of the supernatant was injected into the HPLC system. HPLC conditions were the same as those for the in vitro experiments.

Statistical Evaluation Statistical analysis was done using ANOVA with post hoc Bonferroni-Dunn correction. The level of significance was taken as $p<0.005$.

\section{RESULTS AND DISCUSSION}

Effect of Enhancers on in Vitro Transdermal Permeation of PF Figure 1 shows the cumulative amount perme-
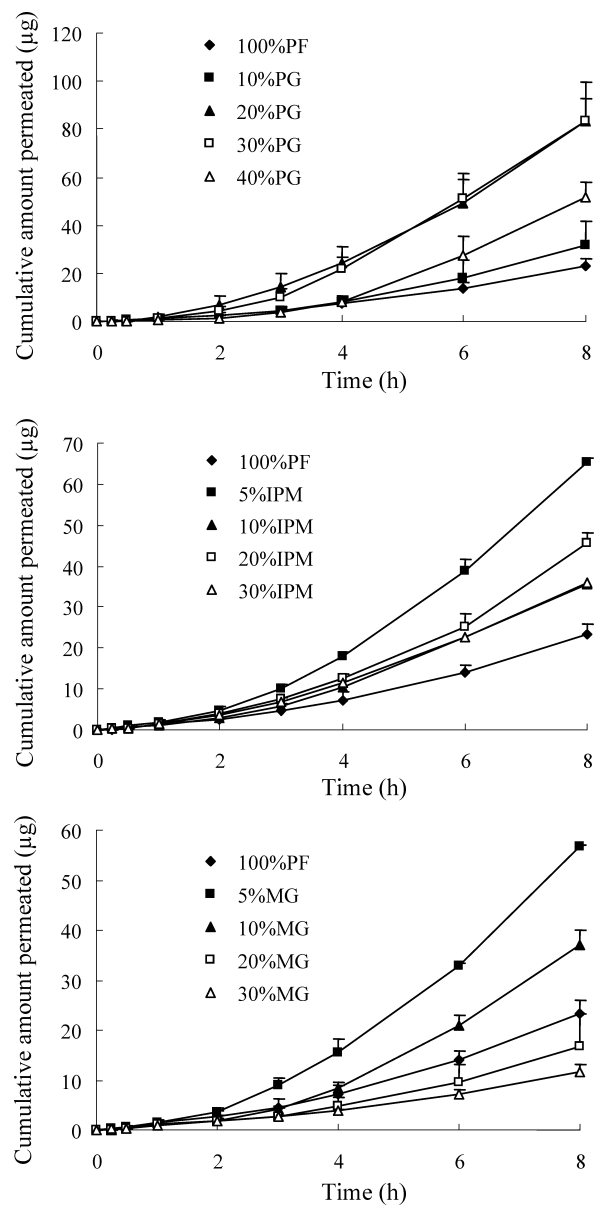

Fig. 1. Influence of Co-solvent Type Enhancers on Transdermal Permeation of $\mathrm{PF}$

Each value represents the mean \pm S.D. $(n=3)$. 
Table 1. Effect of Co-solvent Type Enhancers on the Permeation Parameters of PF through Rat Skin

\begin{tabular}{|c|c|c|c|c|}
\hline & $\begin{array}{c}\text { Cumulative } \\
\text { amount } \\
\text { permeated } \\
(\mu \mathrm{g})\end{array}$ & $\begin{array}{c}J_{S S} \\
\left(\mu \mathrm{g} / \mathrm{h} \cdot \mathrm{cm}^{2}\right)\end{array}$ & $\begin{array}{c}k p \\
\left(\mu \mathrm{g} / \mathrm{h} \cdot \mathrm{cm}^{2}\right)\end{array}$ & $\begin{array}{l}\text { Lag time } \\
\text { (h) }\end{array}$ \\
\hline $100 \% \mathrm{PF}$ & $22.64 \pm 2.20$ & $5.10 \pm 0.25$ & $5.10 \pm 0.25$ & $2.4 \pm 0.4$ \\
\hline \multicolumn{5}{|l|}{ Enhancer } \\
\hline $10 \% \mathrm{PG}$ & $31.51 \pm 3.19$ & $7.55 \pm 2.38$ & $8.48 \pm 2.67$ & $2.9 \pm 0.3$ \\
\hline $20 \%$ PG & $83.21 \pm 16.21$ & $18.78 \pm 3.54 *$ & $23.89 \pm 4.50$ & $2.7 \pm 0.2$ \\
\hline $30 \%$ PG & $83.23 \pm 9.15$ & $19.54 \pm 1.65 *$ & $28.69 \pm 2.42$ & $2.6 \pm 0.4$ \\
\hline $40 \% \mathrm{PG}$ & $51.70 \pm 6.04$ & $13.95 \pm 2.00 *$ & $24.14 \pm 3.46$ & $3.3 \pm 0.4$ \\
\hline $5 \%$ IPM & $65.18 \pm 1.19$ & $15.00 \pm 0.64 *$ & $15.71 \pm 0.67$ & $2.5 \pm 0.1$ \\
\hline $10 \%$ IPM & $35.37 \pm 2.31$ & $7.95 \pm 0.45$ & $9.00 \pm 0.50$ & $2.3 \pm 0.2$ \\
\hline $20 \%$ IPM & $45.70 \pm 1.62$ & $10.58 \pm 0.13 *$ & $12.95 \pm 0.16$ & $2.7 \pm 0.2$ \\
\hline $30 \%$ IPM & $37.42 \pm 0.47$ & $8.30 \pm 0.30$ & $11.50 \pm 0.42$ & $2.3 \pm 0.2$ \\
\hline $5 \% \mathrm{MG}$ & $54.44 \pm 3.75$ & $13.10 \pm 0.72 *$ & $13.91 \pm 0.76$ & $2.8 \pm 0.2$ \\
\hline $10 \% \mathrm{MG}$ & $36.91 \pm 3.19$ & $9.08 \pm 1.19 *$ & $10.26 \pm 1.34$ & $2.9 \pm 0.2$ \\
\hline $20 \% \mathrm{MG}$ & $16.83 \pm 6.58$ & $3.50 \pm 0.90$ & $4.52 \pm 1.17$ & $2.3 \pm 0.3$ \\
\hline $30 \% \mathrm{MG}$ & $11.56 \pm 1.58$ & $2.42 \pm 0.40$ & $3.63 \pm 0.61$ & $2.2 \pm 0.2$ \\
\hline
\end{tabular}

Each value represents the mean \pm S.D. $(n=3) . * p<0.005$ versus $100 \%$ PF.

ated-time profiles after the application of PF solutions containing co-solvent type enhancers. Table 1 shows the cumulative amount of PF that had permeated through skin $8 \mathrm{~h}$ after the application of PF solutions, flux (Jss), permeation coefficient $(k p)$ and lag time. PF solutions containing PG or IPM showed higher values than that of $100 \% \mathrm{PF}$. The highest value was observed $8 \mathrm{~h}$ after the application of PF solution containing $30 \%(\mathrm{w} / \mathrm{w})$ PG. Since the extension of lag time was observed in $40 \%(\mathrm{w} / \mathrm{w}) \mathrm{PG}$, the decrease of drug diffusion through the skin by the decrease of drug concentration in the donor solution was considered. Among PF solutions containing IPM, 5\% IPM showed the highest value. Although PF solutions containing 5 or $10 \%(\mathrm{w} / \mathrm{w}) \mathrm{MG}$ showed higher values than that of $100 \% \mathrm{PF}$, PF solutions containing 20 or $30 \%(\mathrm{w} / \mathrm{w}) \mathrm{MG}$ showed lower values. A previous report on the transdermal delivery of methylxanthine derivatives indicated that PG used as a vehicle showed greater enhancing effects than $\mathrm{MG}^{20)}$ In our findings of transdermal permeation of PF, PG showed greater enhancing effects than MG. Thus, PG showed the highest enhancing effect among co-solvent type enhancers and $J_{S S}$ of PF solution containing $30 \%(\mathrm{w} / \mathrm{w}) \mathrm{PG}$ was approximately four fold that of $100 \% \mathrm{PF}$.

Figures 2-4 and Table 2 show the cumulative amount permeated-time profiles and permeation parameters after the application of PF solutions containing membrane-acting type enhancers. PF solutions containing MEN or LIM showed higher values than that of $100 \%$ PF. Five percent (w/w) MEN and $10 \%(\mathrm{w} / \mathrm{w})$ LIM showed the highest values respectively for the cumulative amount of PF that had permeated through skin $8 \mathrm{~h}$ after the application of PF solutions. Narishetty and Panchagnula suggest that terpenes such as MEN and LIM preferentially form hydrogen bonds with amide groups of stratum corneum lipids and thereby break the inter- and intralamellar hydrogen bonding network of stratum corneum lipids, leading to decreased integrity in the stratum corneum barrier. ${ }^{9)} \mathrm{PF}$ solutions containing OA or SA also showed higher values than that of $100 \% \mathrm{PF}$, and $5 \%(\mathrm{w} / \mathrm{w}) \mathrm{OA}$ and $5 \%(\mathrm{w} / \mathrm{w})$ SA showed the highest values, respectively. Fatty acids such as OA and SA are seen to intercalate and disrupt
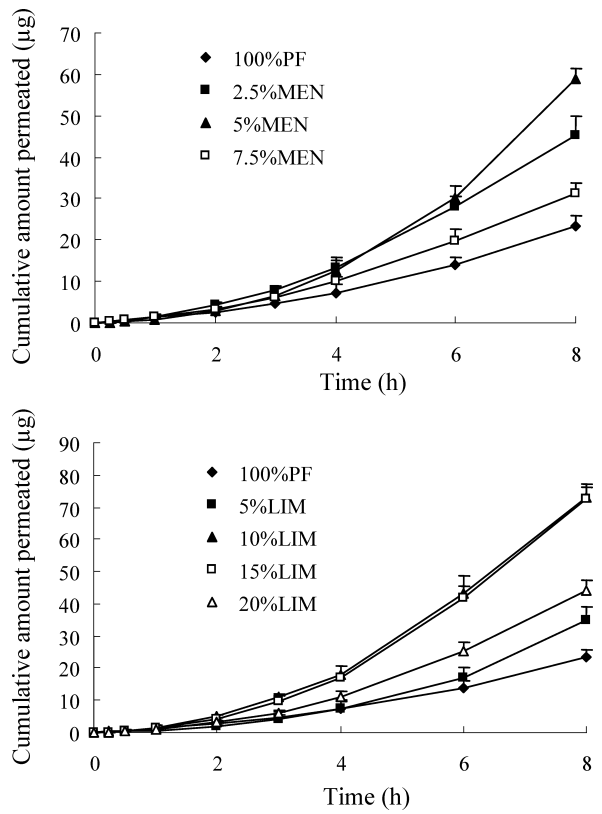

Fig. 2. Influence of MEN or LIM on Transdermal Permeation of PF Each value represents the mean \pm S.D. $(n=3)$.
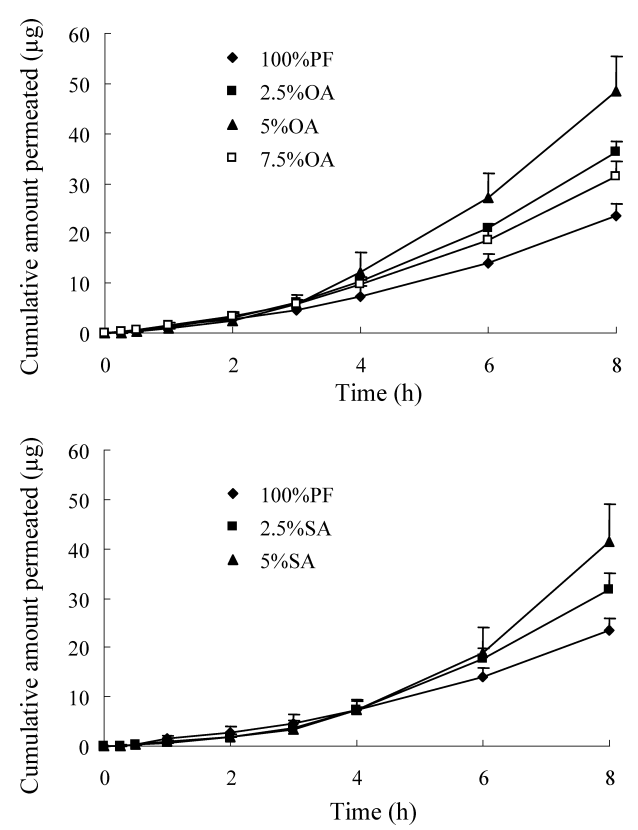

Fig. 3. Influence of OA or SA on Transdermal Permeation of PF Each value represents the mean \pm S.D. $(n=3)$.

the ordered lipid array and form separate fluid states that disorder endogenous lipids. ${ }^{23,24)}$ When the concentration of MEN, LIM and OA was increased the flux of PF was decreased. The optimum concentration of enhancers was observed. Nokhodchi et al. and Rizwan et al. reported similar reduction in penetration enhancement at higher concentration of terpenes..$^{21,22)}$ In this study, the increase of enhancer in a donor solution induced the decrease of PF concentration. Furthermore, interaction by the hydrogen bond between hydroxyl groups of PF and MEN in the donor solution was considered. Activity of PF and MEN decreased by the interaction of intermolecular, and, as a result, the possibility that penetration of PF and MEN decreased each other was con- 


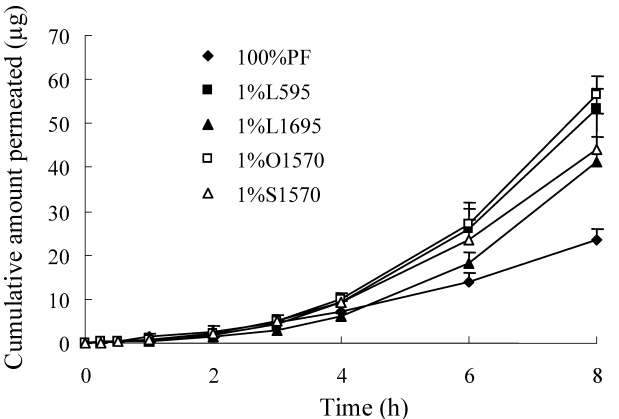

Fig. 4. Influence of Sucrose Fatty Acid Esters on Transdermal Permeation of PF

Each value represents the mean \pm S.D. $(n=3)$.

Table 2. Effect of Membrane-Acting Type Enhancers on the Permeation Parameters of PF through Rat Skin

\begin{tabular}{|c|c|c|c|c|}
\hline Enhancer & $\begin{array}{c}\text { Cumulative } \\
\text { amount } \\
\text { permeated } \\
(\mu \mathrm{g})\end{array}$ & $\begin{array}{c}J_{S S} \\
\left(\mu \mathrm{g} / \mathrm{h} \cdot \mathrm{cm}^{2}\right)\end{array}$ & $\begin{array}{c}k p \\
\left(\mu \mathrm{g} / \mathrm{h} \cdot \mathrm{cm}^{2}\right)\end{array}$ & $\begin{array}{l}\text { Lag time } \\
\text { (h) }\end{array}$ \\
\hline $2.5 \% \mathrm{MEN}$ & $45.38 \pm 1.29$ & $10.26 \pm 4.56 *$ & $10.52 \pm 1.33$ & $2.4 \pm 0.3$ \\
\hline $5 \% \mathrm{MEN}$ & $58.29 \pm 2.47$ & $14.73 \pm 1.37 *$ & $15.51 \pm 1.45$ & $3.1 \pm 0.5$ \\
\hline $7.5 \% \mathrm{MEN}$ & $31.41 \pm 2.43$ & $6.49 \pm 0.29$ & $7.02 \pm 0.32$ & $2.1 \pm 0.1$ \\
\hline 5\% LIM & $34.71 \pm 4.21$ & $8.75 \pm 0.71 *$ & $9.21 \pm 0.74$ & $3.1 \pm 0.4$ \\
\hline $10 \%$ LIM & $73.05 \pm 4.19$ & $17.61 \pm 0.50 *$ & $19.59 \pm 0.55$ & $2.8 \pm 0.2$ \\
\hline $15 \%$ LIM & $72.59 \pm 3.73$ & $17.74 \pm 0.43 *$ & $20.87 \pm 0.50$ & $2.9 \pm 0.3$ \\
\hline 20\% LIM & $43.94 \pm 3.38$ & $10.45 \pm 0.97 *$ & $13.07 \pm 1.21$ & $2.7 \pm 0.3$ \\
\hline $2.5 \% \mathrm{OA}$ & $36.32 \pm 5.76$ & $8.26 \pm 0.58^{*}$ & $8.47 \pm 0.60$ & $2.5 \pm 0.1$ \\
\hline $5 \% \mathrm{OA}$ & $48.19 \pm 7.33$ & $12.55 \pm 0.57 *$ & $13.21 \pm 0.59$ & $2.7 \pm 0.4$ \\
\hline $7.5 \% \mathrm{OA}$ & $31.50 \pm 2.86$ & $7.09 \pm 0.23$ & $7.66 \pm 0.25$ & $2.4 \pm 0.3$ \\
\hline $2.5 \% \mathrm{SA}$ & $31.64 \pm 3.25$ & $7.79 \pm 0.78$ & $7.99 \pm 0.80$ & $2.9 \pm 0.1$ \\
\hline $5 \% \mathrm{SA}$ & $41.44 \pm 7.63$ & $10.89 \pm 2.35^{*}$ & $11.46 \pm 2.48$ & $3.3 \pm 0.1$ \\
\hline $1 \%$ L595 & $53.43 \pm 7.33$ & $14.00 \pm 1.75^{*}$ & $14.14 \pm 1.77$ & $3.3 \pm 0.1$ \\
\hline 1\% L1695 & $41.28 \pm 5.79$ & $11.17 \pm 1.67 *$ & $11.29 \pm 1.69$ & $3.5 \pm 0.0$ \\
\hline $1 \% \mathrm{O} 1570$ & $56.56 \pm 1.34$ & $14.80 \pm 0.76^{*}$ & $14.95 \pm 0.77$ & $3.3 \pm 0.2$ \\
\hline $1 \% \mathrm{~S} 1570$ & $44.14 \pm 7.95$ & $11.06 \pm 2.17 *$ & $11.18 \pm 2.19$ & $3.0 \pm 0.1$ \\
\hline
\end{tabular}

Each value represents the mean \pm S.D. $(n=3) . * p<0.005$ versus $100 \%$ PF.

sidered. In LIM not having hydroxyl groups, the influence of the interaction with PF is lower than MEN. The influence of the decrease of PF concentration in the donor solution should be larger. Since the solubility of sucrose fatty acid esters to $\mathrm{PF}$ was low, the experiments were performed using only PF solutions containing $1 \%(\mathrm{w} / \mathrm{w})$ sucrose fatty acid ester. PF solutions containing sucrose fatty acid esters showed higher values than that of $100 \%$ PF. Sucrose fatty acid ester is a nonionic detergent used for food as an emulsifying agent. Recently, sucrose fatty acid esters have attracted attention as enhancers for transdermal delivery. ${ }^{13)}$ From these results, PF solutions containing membrane-acting type enhancers showed higher values than that of $100 \% \mathrm{PF}$, and 10 and $15 \%$ (w/w) LIM showed the highest values.

Figure 5 and Table 3 show the cumulative amount permeated-time profiles and permeation parameters after application of PF solutions containing co-solvent type enhancers. The enhancing effect of $5 \%(\mathrm{w} / \mathrm{w}) \mathrm{MG}-25 \%(\mathrm{w} / \mathrm{w})$ PG was almost the same as that of $30 \%(\mathrm{w} / \mathrm{w})$ PG. There was no apparent synergistic effect of the combined use of co-solvent type enhancers. The enhancement effect of $5 \%(\mathrm{w} / \mathrm{w})$ IPM-25\% (w/w) PG was worse than that of $30 \%(\mathrm{w} / \mathrm{w})$ PG. Since PG showed greater enhancing effect among the co-sol-

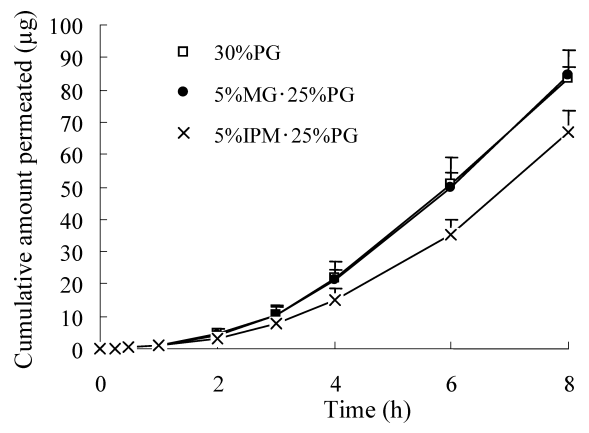

Fig. 5. Influence of PG and IPM or MG on Transdermal Permeation of PF Each value represents the mean \pm S.D. $(n=3)$.

Table 3. Effect of Combining PG with Other Enhancers on the Permeation Parameters of PF through Rat Skin

\begin{tabular}{|c|c|c|c|c|}
\hline Enhancer & $\begin{array}{l}\text { Cumulative } \\
\text { amount } \\
\text { permeated } \\
(\mu \mathrm{g})\end{array}$ & $\begin{array}{c}J_{S S} \\
\left(\mu \mathrm{g} / \mathrm{h} \cdot \mathrm{cm}^{2}\right)\end{array}$ & $\begin{array}{c}k p \\
\left(\mu \mathrm{g} / \mathrm{h} \cdot \mathrm{cm}^{2}\right)\end{array}$ & $\begin{array}{l}\text { Lag time } \\
\text { (h) }\end{array}$ \\
\hline $5 \% \mathrm{IPM} \cdot 25 \% \mathrm{PG}$ & $67.09 \pm 6.64$ & $16.40 \pm 0.90 *$ & $23.84 \pm 1.31$ & $3.0 \pm 0.2$ \\
\hline $5 \% \mathrm{MG} \cdot 25 \% \mathrm{PG}$ & $84.57 \pm 2.49$ & $20.19 \pm 0.19^{*}$ & $29.73 \pm 0.28$ & $2.7 \pm 0.2$ \\
\hline \multicolumn{5}{|c|}{ 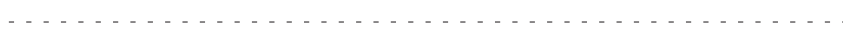 } \\
\hline $5 \% \mathrm{MEN} \cdot 25 \% \mathrm{PG}$ & $118.80 \pm 6.14$ & $28.21 \pm 0.95^{*}$ & $41.31 \pm 1.39$ & $2.8 \pm 0.5$ \\
\hline $5 \% \mathrm{MEN} \cdot 30 \% \mathrm{PG}$ & $83.24 \pm 7.82$ & $18.92 \pm 1.03^{*}$ & $29.94 \pm 1.63$ & $2.5 \pm 0.4$ \\
\hline $10 \% \mathrm{LIM} \cdot 20 \% \mathrm{PG}$ & $53.37 \pm 3.33$ & $12.92 \pm 0.64^{*}$ & $18.92 \pm 0.93$ & $2.8 \pm 0.4$ \\
\hline $5 \% \mathrm{LIM} \cdot 25 \% \mathrm{PG}$ & $82.15 \pm 5.76$ & $19.58 \pm 1.11^{*}$ & $28.55 \pm 1.62$ & $2.8 \pm 0.4$ \\
\hline $5 \% \mathrm{OA} \cdot 25 \% \mathrm{PG}$ & $85.20 \pm 10.58$ & $20.26 \pm 2.07 *$ & $29.66 \pm 3.03$ & $2.7 \pm 0.2$ \\
\hline $5 \% \mathrm{SA} \cdot 25 \% \mathrm{PG}$ & $73.46 \pm 11.70$ & $17.96 \pm 2.82 *$ & $26.30 \pm 4.12$ & $2.9 \pm 0.2$ \\
\hline $1 \% \mathrm{O} 1570 \cdot 25 \% \mathrm{PG}$ & $101.93 \pm 7.01$ & $26.89 \pm 2.26^{*}$ & $39.42 \pm 3.32$ & $3.3 \pm 0.2$ \\
\hline $1 \% \mathrm{O} 1570 \cdot 29 \% \mathrm{PG}$ & $130.46 \pm 12.16$ & $31.67 \pm 3.68^{*}$ & $43.80 \pm 5.09$ & $2.9 \pm 0.4$ \\
\hline $1 \% \mathrm{~S} 1570 \cdot 25 \% \mathrm{PG}$ & $102.45 \pm 5.51$ & $25.56 \pm 1.59^{*}$ & $35.35 \pm 2.20$ & $3.0 \pm 0.1$ \\
\hline $1 \% \mathrm{~S} 1570 \cdot 29 \% \mathrm{PG}$ & $121.51 \pm 13.63$ & $30.26 \pm 4.24^{*}$ & $44.37 \pm 6.22$ & $3.0 \pm 0.3$ \\
\hline $1 \% \mathrm{~L} 595 \cdot 25 \% \mathrm{PG}$ & $146.52 \pm 14.43$ & $38.93 \pm 4.16^{*}$ & $53.84 \pm 5.75$ & $3.4 \pm 0.3$ \\
\hline $1 \% \mathrm{~L} 595 \cdot 29 \% \mathrm{PG}$ & $120.47 \pm 7.02$ & $30.43 \pm 3.59^{*}$ & $42.09 \pm 0.97$ & $3.0 \pm 0.4$ \\
\hline $1 \% \mathrm{~L} 1695 \cdot 25 \% \mathrm{PG}$ & $86.44 \pm 5.68$ & $21.39 \pm 1.68^{*}$ & $31.36 \pm 2.46$ & $2.9 \pm 0.2$ \\
\hline $1 \% \mathrm{~L} 1695 \cdot 29 \% \mathrm{PG}$ & $147.44 \pm 13.17$ & $36.39 \pm 2.13^{*}$ & $50.74 \pm 2.94$ & $3.0 \pm 0.5$ \\
\hline $1 \% \mathrm{SDS} \cdot 25 \% \mathrm{PG}$ & $117.47 \pm 5.29$ & $27.73 \pm 1.63^{*}$ & $38.36 \pm 2.26$ & $2.7 \pm 0.6$ \\
\hline $1 \% \operatorname{SDS} \cdot 29 \% \mathrm{PG}$ & $157.27 \pm 10.34$ & $39.32 \pm 3.45^{*}$ & $57.76 \pm 5.06$ & $3.0 \pm 0.2$ \\
\hline
\end{tabular}

Each value represents the mean \pm S.D. $(n=3) . * p<0.005$ versus $100 \%$ PF.

vent type enhancers, effects of combining PG with membrane-acting type enhancers was investigated. Figures 6, 7 and Table 3 show the cumulative amount permeated-time profiles and permeation parameters after the application of PF solutions containing PG and membrane-acting type enhancers. Five percent (w/w) MEN-25\% (w/w) PG showed the higher enhancing effect than $30 \%(\mathrm{w} / \mathrm{w})$ PG. However, the enhancing effect of 5\% (w/w) MEN-30\% (w/w) PG was almost the same as $30 \%(\mathrm{w} / \mathrm{w})$ PG. The $k p$ value of $5 \%$ (w/w) MEN-30\% (w/w) PG was lower than 5\% (w/w) MEN-25\% (w/w) PG. The transdermal permeation of PF was reduced more than the decrease in PF concentration. These findings suggest that the PF concentration should be higher than $70 \%(\mathrm{w} / \mathrm{w})$ for effective delivery of PF through the skin. Although the enhancing effects of $5 \%(\mathrm{w} / \mathrm{w})$ LIM-25\% (w/w) PG were almost the same as those of $30 \%$ (w/w) PG, the enhancement effect of 10\% (w/w) LIM-20\% (w/w) PG were decreased. LIM showed enhancing effects at a relatively high concentration. Furthermore, it was reported that transdermal permeation was enhanced by the simultaneous use of LIM and a large amount of alcohol. ${ }^{8)}$ Since the usage of a large amount of PG and LIM decreases the PF 

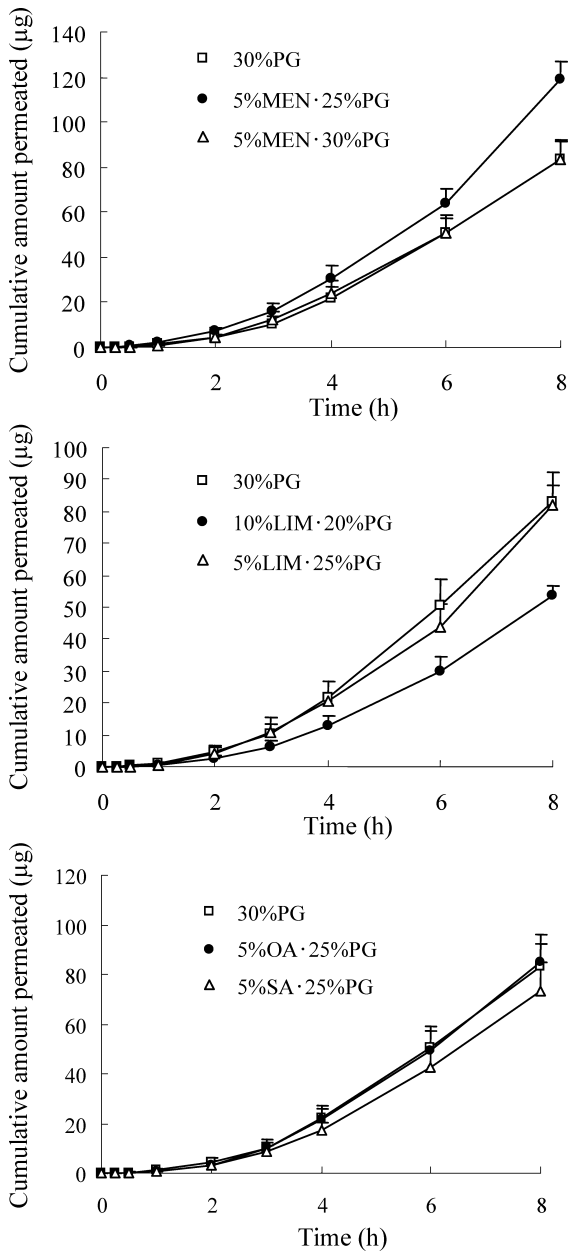

Fig. 6. Influence of PG and Membrane-Acting Type Enhancers on Transdermal Permeation of PF

Each value represents the mean \pm S.D. $(n=3)$.

concentration, the combination of PG and LIM does not effectively facilitate for the transdermal permeation of PF. The combined effect of PG and OA or SA was also comparable to that of $30 \%(\mathrm{w} / \mathrm{w})$ PG. Based on these results, there was no effect of combining PG with OA or SA on the transdermal permeation of PF. The combination of PG and sucrose fatty acid esters showed a greater enhancing effect than $30 \%$ (w/w) PG. Sucrose fatty acids with a high HLB value, O1570, S1570, L1695, showed a higher enhancing effect when combined with a large amount of PG. In contrast, L595 with a low HLB value showed a higher enhancing effect when combined with a smaller amount of PG. In addition to sucrose fatty acid esters, we also investigated the enhancing effect of combining SDS, one of surfactants, with PG. The combination of $\mathrm{PG}$ and SDS also provided a greater enhancing effect than $30 \%(\mathrm{w} / \mathrm{w})$ PG. In Table 3, higher values on permeation parameters were observed in $1 \%(\mathrm{w} / \mathrm{w})$ L595-25\% (w/w) PG, 1\% (w/w) L1695-29\% (w/w) PG and $1 \%(\mathrm{w} / \mathrm{w})$ SDS-29\% (w/w) PG. It was interesting that the combination of $\mathrm{PG}$ and lauric acid derivatives induced higher values on permeation parameters. These findings suggest that combinations of PG with MEN, sucrose fatty acid esters or SDS were suitable enhancers for the transdermal delivery of PF.

Effect of Enhancers on in Vivo Transdermal Absorp-
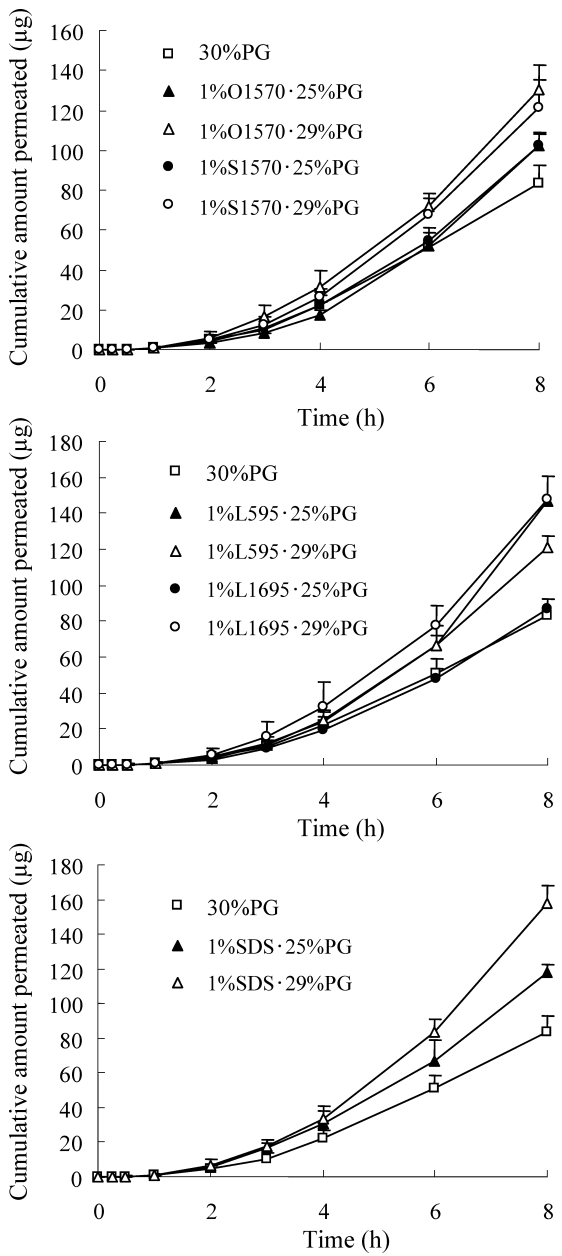

Fig. 7. Influence of PG and Sucrose Fatty Acid Esters or SDS on Transdermal Permeation of PF

Each value represents the mean \pm S.D. $(n=3)$.

Table 4. AUC after Transdermal Administration of PF Solutions Containing PG

\begin{tabular}{cc}
\hline \hline & $A U C(\mathrm{ng} \cdot \mathrm{h} / \mathrm{ml})$ \\
\hline $100 \%$ PF & $925 \pm 70$ \\
Enhancer & $1337 \pm 178$ \\
$1 \%$ PG & $1740 \pm 151^{*}$ \\
$5 \%$ PG & $1460 \pm 63^{*}$ \\
$10 \%$ PG & $1237 \pm 141$ \\
$20 \%$ PG & $312 \pm 61$ \\
$30 \%$ PG & \\
\hline
\end{tabular}

Each value represents the mean \pm S.E. $(n=3) . * p<0.005$ versus $100 \%$ PF.

tion of PF Plasma concentration profiles of $\mathrm{PF}$ and the area under the plasma concentration-time curve $(A U C)$ after the transdermal administration of $100 \% \mathrm{PF}$ and $\mathrm{PF}$ solutions containing PG are shown in Fig. 1 and Table 4. Although $30 \%(w / w)$ PG was the optimal concentration to enhance the in vitro transdermal permeation of $\mathrm{PF}$, the plasma concentration of PF after administration of PF solution containing 30\% (w/w) PG were lower than that after administration of $100 \%$ $\mathrm{PF}$. In contrast, the plasma concentration of $\mathrm{PF}$ and $A U C$ after the administration of PF solution containing 1, 5, 10 or $20 \%(w / w)$ PG was increased compared with that after ad- 


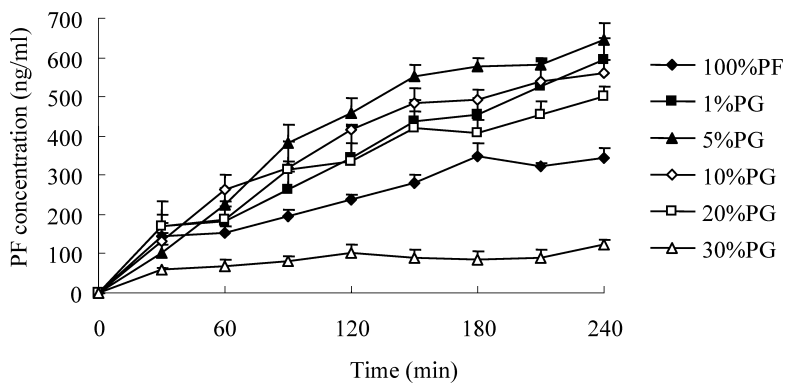

Fig. 8. Plasma Concentration Profiles of PF after Transdermal Administration of PF Solutions Containing PG

$$
\text { Each value represents the mean } \pm \text { S.E. }(n=3) \text {. }
$$
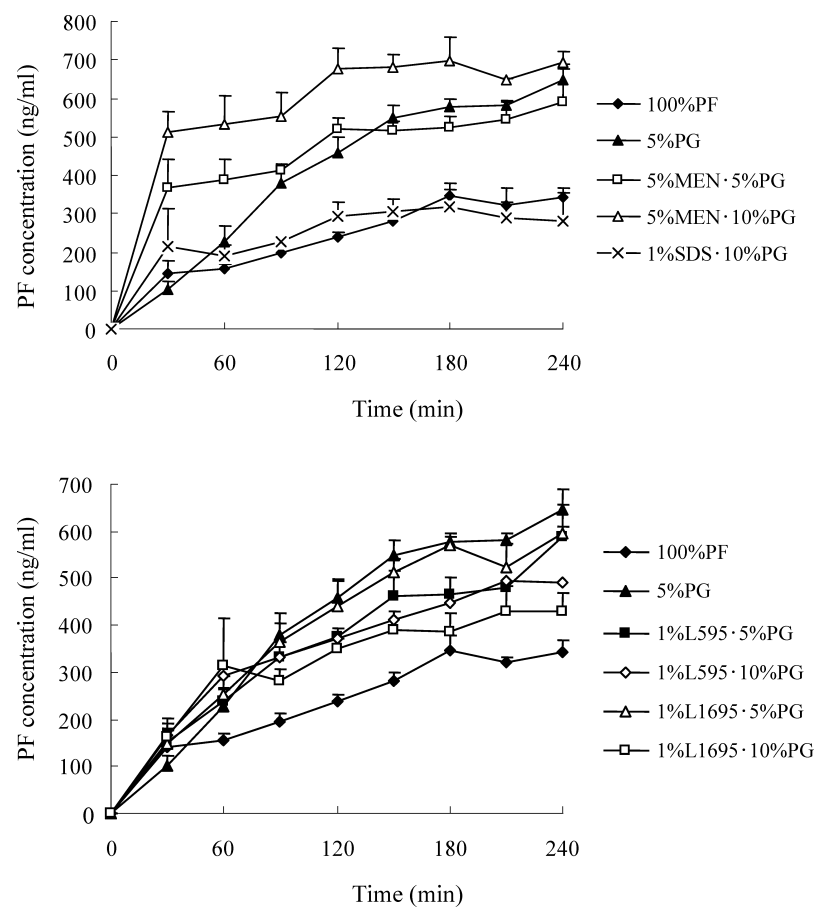

Fig. 9. Plasma Concentration Profiles of PF after Transdermal Administration of PF Solutions Containing PG and MEN, SDS or Sucrose Fatty Acid Esters

Each value represents the mean \pm S.E. $(n=3)$.

ministration of $100 \%$ PF. The optimal PG concentration in the in vivo experiments was not consistent with that in the in vitro experiments. PF must be delivered through the epidermis, dermis and hypodermis to achieve in vitro transdermal permeation. Since the dermis is hydrophilic, lipophilic PF might achieve permeation with the flow of PG. In contrast, since PF was absorbed through the capillary vessels in the upper dermis during the in vivo trial, the lipophilicity of the donor solution containing a small amount of PG might be effective. Yano et al. reported that the optimal $\log$ P (octanolwater partition coefficient) value of nonsteroidal anti-inflammatory drugs for transdermal absorption was $2-3 .{ }^{25}$ ) The $\log \mathrm{P}$ value of PF listed in the drug information form prepared by Astra Zeneca is 3.8. Hence, the addition of a small amount of PG might be sufficient to obtain optimal lipophilicity of the donor solution.

The plasma concentration profiles of $\mathrm{PF}$ and $A U C$ after transdermal administration of PF solutions containing PG and membrane-acting type enhancers are shown in Fig. 2 and
Table 5. AUC after Transdermal Administration of PF Solutions Containing PG and Membrane-Acting Type Enhancers

\begin{tabular}{cc}
\hline \hline Enhancer & $A U C(\mathrm{ng} \cdot \mathrm{h} / \mathrm{ml})$ \\
\hline $5 \% \mathrm{MEN} \cdot 5 \% \mathrm{PG}$ & $1779 \pm 14^{*}$ \\
$5 \% \mathrm{MEN} \cdot 10 \% \mathrm{PG}$ & $2321 \pm 132^{*}$ \\
$1 \% \mathrm{SDS} \cdot 10 \% \mathrm{PG}$ & $985 \pm 76$ \\
$1 \% \mathrm{~L} 55 \cdot 5 \% \mathrm{PG}$ & $1395 \pm 99^{*}$ \\
$1 \% \mathrm{~L} 595 \cdot 10 \% \mathrm{PG}$ & $1376 \pm 71$ \\
$1 \% \mathrm{~L} 1695 \cdot 5 \% \mathrm{PG}$ & $1552 \pm 134^{*}$ \\
$1 \% \mathrm{~L} 1695 \cdot 10 \% \mathrm{PG}$ & $1261 \pm 93$ \\
\hline
\end{tabular}

Each value represents the mean \pm S.E. $(n=3) . * p<0.005$ versus $100 \%$ PF.
A

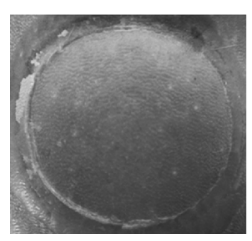

B

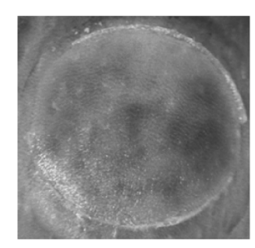

C

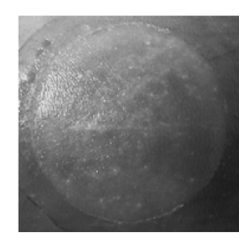

Fig. 10. Photographs of Abdominal Skin after Transdermal Administration of PF Solutions

(A) $100 \% \mathrm{PF}$, (B) PF solution containing $1 \% \mathrm{SDS} \cdot 10 \% \mathrm{PG}$, (C) PF solution containing $5 \% \mathrm{MEN} \cdot 10 \% \mathrm{PG}$.

Table 5. In the in vitro experience, the combinations of PG with MEN, sucrose fatty acid esters or SDS were suitable as enhancers. Hence, the combination of PG and MEN, sucrose fatty acid esters or SDS was investigated. A higher plasma concentration level was achieved $30 \mathrm{~min}$ after the application of $5 \%(\mathrm{w} / \mathrm{w}) \mathrm{MEN}-10 \%(\mathrm{w} / \mathrm{w}) \mathrm{PG}$, and a value of approximately 2.5 times the $A U C$ of $100 \%$ PF was obtained. In the previous study, we reported that the plasma concentration of approximately $500 \mathrm{ng} / \mathrm{ml}$ of PF induced a sedative or drowsy state in rats. ${ }^{17)} \mathrm{PF}$ solution containing $5 \%(\mathrm{w} / \mathrm{w}) \mathrm{MEN}-10 \%$ (w/w) PG provided a high plasma concentration level of over $500 \mathrm{ng} / \mathrm{ml}$ at $30 \mathrm{~min}$, and the concentration was maintained for $4 \mathrm{~h}$. Although MEN achieved enhancement from the early period when $5 \%(\mathrm{w} / \mathrm{w})$ MEN-5\% (w/w) PG was used, the $A U C$ was almost the same as that of $5 \%(\mathrm{w} / \mathrm{w})$ PG. Previous work has indicated that PG by itself does not interfere with membranes, but rather exhibits a synergistic effect in combination with other penetration enhancers. When PG was added in conjunction with other membrane-acting type enhancers, a significant perturbation of the lipid assembly was observed. ${ }^{26)}$ Since it is considered that PG enhances the delivery of MEN into the stratum corneum, $5 \%(\mathrm{w} / \mathrm{w})$ PG might not be sufficient for the dissolution and permeation of MEN. The plasma concentration levels after the application of PF solutions containing 1\% (w/w) L595 or L1695 and 5 or $10 \%(\mathrm{w} / \mathrm{w})$ PG were not increased compared with that of $5 \%$ PG. The sucrose fatty acid esters used were not readily dissolved in PF, and the solubility was improved by adding PG. The sucrose fatty acid esters might dissolve and achieve an enhancing effect in combination with a large amount of PG. However, the addition of a large amount of PG lowered the PF concentration and lipophilicity of the donor solution. Hence, the combination of PG and sucrose fatty acid esters was not suitable for the transdermal delivery of $\mathrm{PF}$ in vivo. Plasma concentration levels after the application of PF solutions containing $1 \%(\mathrm{w} / \mathrm{w})$ SDS and $10 \%(\mathrm{w} / \mathrm{w})$ PG were 
also decreased as compared with that of 5\% PG. Photographs of abdominal skin treated with PF solutions obtained after the in vivo experiments are shown in Fig. 3. There was no visually apparent irritation after the application of $100 \%$ PF. Although the skin color changed slightly after the application of PF solution containing 5\% (w/w) MEN-10\% (w/w) PG, irritation was moderate compared with that caused by PF solution containing 1\% (w/w) SDS and 10\% (w/w) PG. Based on the above results, it was considered that the plasma PF concentration was decreased as a result of necrotic changes in the tissue after the administration of PF solution containing $1 \%(\mathrm{w} / \mathrm{w})$ SDS and $10 \%(\mathrm{w} / \mathrm{w})$ PG. Thus, the combination of PG and SDS was not suitable for transdermal delivery of $\mathrm{PF}$ in vivo.

\section{CONCLUSION}

The effects of enhancers on in vitro transdermal permeation and in vivo transdermal absorption of PF were investigated. Among the co-solvent type enhancers, PG showed the highest enhancing effect and JSS of PF solution containing $30 \%$ (w/w) PG was approximately fourfold that of $100 \% \mathrm{PF}$ in vitro. Furthermore, the synergistic effect of combining PG with membrane-acting type enhancers was confirmed. However, the optimal PG concentration in the in vitro experiments was not consistent with that in the in vivo experiments. The highest value of $A U C$ was observed after the administration of PF solution containing 5\% (w/w) PG in vivo. The synergistic effect of $\mathrm{PG}$ and membrane-acting type enhancers was achieved in 5\% (w/w) MEN-10\% (w/w) PG. The high plasma concentration level was observed $30 \mathrm{~min}$ after the administration of PF solution containing 5\% (w/w) MEN-10\% $(\mathrm{w} / \mathrm{w}) \mathrm{PG}$, and higher concentration was maintained for $4 \mathrm{~h}$. The combination of PG and sucrose fatty acid esters or SDS was not suitable for transdermal delivery of PF in vivo. Our findings suggest that the combination of PG and MEN was useful for enhancing the transdermal absorption of PF. These results provide useful information for the development of a transdermal dosage form of PF as sedative or hypnotic.

Acknowledgements This work was supported by the Ministry of Education, Culture, Sports, Science and Technology of Japan. We appreciate the experimental assistance of Mr. Yasuhiro Motizuki and Ms. Tomoe Date.

\section{REFERENCES}

1) Yata N., Jpn. J. Clin. Med., 56, 608-612 (1998).

2) Banga A. K., Chien Y. W., J. Controlled Release, 7, 1-24 (1988).

3) Lin H. H., Hsu L. R., Wu P. C., Tsai Y. H., Biol. Pharm. Bull., 18, $1560-1565$ (1995)

4) Cooper E. R., J. Pharm. Sci., 73, 1153-1156 (1982)

5) Ogiso T., Koike K., Iwaki M., Tanino T., Tanabe G., Muraoka O., Biol. Pharm. Bull., 23, 844-849 (2000).

6) Jiang S. J., Zhou X. J., Biol. Pharm. Bull., 26, 66-68 (2002).

7) Nanayakkara G. R., Bartlett A., Forbes B., Marriott C., Whitfield P. J., Brown M. B., Int. J. Pharm., 301, 129-139 (2005).

8) Obata Y., Takayama K., Machida Y., Nagai T., Drug Dev. Discov., 8, 137-144 (1991).

9) Narishetty S. T. K., Panchagnula R., J. Controlled Release, 102, 5970 (2005).

10) Amnuaikit C., Ikeuchi I., Ogawara K., Higaki K., Kimura T., Int. J. Pharm., 289, 167-178 (2005).

11) Nokhodchi A., Shokri J., Dashbolaghi A., Zadeh D. H., Ghafourian T., Jalali M. B., Int. J. Pharm., 250, 359-369 (2003).

12) Ayala-Bravo H. A., Quintanar-Guerrero D., Naik A., Kalia Y. N., Cornejo-Bravo J. M., Ganem-Quintanar A., Pharm. Res., 20, 12671273 (2003).

13) Okamoto H., Sakai T., Danjo K., Biol. Pharm. Bull., 28, 1689-1694 (2005).

14) Brinkmann I., Muller-Goymann C. C., Pharmazie, 60, 215-220 (2005).

15) Catz P., Friend D. R., Int. J. Pharm., 58, 93-102 (1990).

16) Funke A. P., Schiller R., Motzkus H. W., Gunther C., Muller R. H., Lipp R., Pharm. Res., 19, 661-668 (2002).

17) Takahashi Y., Yamato K., Akiyama H., Tsuji K., Onishi H., Machida Y., Biol. Pharm. Bull., 28, 870-875 (2005).

18) Funke A. P., Gunther C., Muller R. H., Lipp R., J. Controlled Release, 82, 63-70 (2002).

19) Servin F., Desmonts J. M., Haberer J. P., Cockshott I. D., Plummer G. F., Farinotti R., Anesthesiology, 69, 887-891 (1988).

20) Heard C. M., Johnson S., Moss G.., Thomas C. P., Int. J. Pharm., 317, 26-31 (2006).

21) Nokhodchi A., Sharabiani K., Rashidi M. R., Ghafourian T., Int. J. Pharm., 335, 97-105 (2007).

22) Rizwan M., Aqil M., Ahad A., Sultana Y., Ali M. M., Drug Dev. Ind. Pharm., 34, 618-626 (2008).

23) Naik A., Pechtold L., Potts R. O., Guy R. H., J. Controlled Release, 37, 299-306 (1995).

24) Ongpipattanakul B., Burnette R. R., Potts R. O., M.L. Francoeur M. L., Pharm. Res., 8, 350-354 (1991).

25) Yano T., Nakagawa A., Tsuji M., Noda K., Life Sci., 39, 1043-1050 (1986).

26) Evrard D., Touitou E., Kolusheva S., Fishov Y., Jelinek R., Pharm. Res., 18, 943-949 (2001). 